\title{
EXPERIMENTAL STUDY OF TERNARY FUEL BLENDS ON AN ASTM-CFR-CETANE ENGINE
}

\author{
H. L. Rocha a \\ N. R. Pinto ${ }^{a}$, \\ M. J. Colaço ${ }^{a}$, \\ and A. J. K. Leiroz ${ }^{\mathrm{b}}$ \\ ${ }^{a}$ Universidade Federal do Rio de Janeiro \\ Departamento de Engenharia Mecânica \\ Escola Politécnica/COPPE \\ Cidade Universitária \\ CEP 21941-972, Rio de Janeiro, RJ, Brasil \\ hlobianco@ poli.ufrj.br \\ nauberto@1mt.coppe.ufrj.br \\ colaco@asme.org \\ leiroz@mecanica.ufrj.br
}

Received: October 29, 2014

Revised: November 30, 2014

Accepted: December 30, 2014
ABSTRACT

This work analyses how ternary blends of biodiesel, anhydrous and hydrous ethanol, and diesel, in different proportions, behave regarding fuel emissions and combustion parameters. The determination of their cetane number, using an ASTM-CFR cetane research engine is also investigated. The base fuels used were $99,9 \%$ pure anhydrous ethanol, commercial diesel, which contains $5 \%$ of biodiesel in volume, biodiesel from soybean oil, and hydrous ethanol with $7 \%$ of water, in volume. The fuel blends were specified after a careful bibliography research. Five volume fractions of biodiesel $(5,10,20,60$ and $100 \%$, in volume) and four of ethanol $(0,5,8$ and $15 \%$, also in volume) were used in this study. All blends have endured a mixture stability test prior to being burned, the ones with clear visual phase separation being eventually rejected. The results for the cetane number presented a clear decrease in its value as ethanol was added. Some blends with high ethanol content failed to provide the minimum cetane number for use in compression ignition engines according to the present Brazilian regulations. Concerning the emissions tests, carbon dioxide emissions showed a decreasing trend as the quantity of added ethanol raised. Carbon monoxide emissions, however, showed the opposite trend. The nitrogen oxides emissions presented an increase as more biodiesel was added to the blend. The conclusions as to the impact of changing ethanol's volume in the blends were discussed taking in consideration important operational remarks. A final analysis was proposed in order to compare anhydrous and hydrous ethanol. A clear reduction in nitrogen oxides and carbon dioxide emissions was observed, with an almost identical value for the carbon monoxide emissions. Cetane number for the hydrous ethanol blend, however, suffered a decrease compared to the same blend with anhydrous ethanol.

Keywords: ternary fuel blends, experimental project, cetane number, emissions

\section{NOMENCLATURE}

Bx dimensionless quantity of biodiesel, in which $\mathrm{x}$ indicates the $\%$ of biodiesel in volume in the blend

Ey dimensionless quantity of ethanol, in which y indicates the \% of ethanol in volume in the blend

BxEy dimensionless ternary blend of ethanol, biodiesel and diesel in which $\mathrm{x}$ indicates the $\%$ of biodiesel in volume in the blend and $y$ indicates the $\%$ of ethanol in volume in the blend

BxEyH dimensionless ternary blend in which hydrous ethanol was used instead of anhydrous ethanol

$\mathrm{CN}$ dimensionless cetane number

$\mathrm{KOH}$ dimensionless potassium hydroxide

\section{Greek symbols}

$\rho \quad$ density, $\mathrm{kg} / \mathrm{m}^{3}$

$v \quad$ fluid kinematic viscosity, $\mathrm{m}^{2} / \mathrm{s}$ $\theta \quad$ dimensionless degrees

\section{INTRODUCTION}

Brazil is largely dependent on the consumption of diesel fuel, both for power generation and transportation. Since trucks that use diesel engines transport most of the goods in Brazil, the usage of this fuel and the analysis of the associated engine performance and emissions is of utmost importance for the country's development and also for the environment protection (Brasil, 2014a).

Although the country has large reserves of petroleum, most of the diesel fuel is still imported (Brasil, 2014b). Thus, the analysis of performance and emissions of diesel engines is important to reduce the country's dependence on imported fuel, in order to reduce its associated costs, and also for strategic reasons. There is also an interest in reducing the gaseous emissions of diesel engines, to minimize their impact over the environment.

The Brazilian Ministry of the Environment, through the Program for the Control of Air Pollution 
from Motor Vehicles (PROCONVE), together with the Brazilian National Agency of Petroleum, Natural Gas and Biofuels (ANP) and other agencies, has determined several goals to be followed by fuel and engine manufactures in order to reduce the gaseous and particulate matter emissions (Brasil, 2014c). Such determinations have put the country on the same level of engine efficiency and emissions as many developed countries. However, even with high efficient engines, the number of sales of new trucks in Brazil has increased in recent years, mainly due to the economic boom after 2008. As a consequence, the volume of imported fuel has reached new records in the last years. All these factors, including the economic dependence of foreign countries, strategic reasons and the impact on the environment, have guided recent researches to obtain cleaner and more efficient diesel engines. One of the possibilities for reducing the dependence of imported fuel is to use biofuels. A critical issue, however, is the fact the soil is disputed between food and fuel production.

This paper aims to contribute to the research in biofuels, to be added to commercial diesel fuel, in order to reduce the pollution to the environment and the total amount of fossil fuel consumed. This has to be accomplished while maintaining safety standards for the fuel use, without requiring changes to existing vehicles.

Ternary mixtures are those in which three distinct components are combined to form a single and homogeneous mixture. Cruz (2009) and LaPuerta et al. (2007) reported that blends of diesel and ethanol are stable up to $3 \%$ (in volume) of ethanol in the mixture. When larger amounts of ethanol are introduced, the components may become unstable. This is due, among other factors, to the fact that the diesel molecule is nonpolar, while the ethanol molecule is polar. To remedy such problem some additives can be used (Cruz, 2009; La Puerta et al., 2007) to enhance the homogeneity of the diesel and ethanol mixture. With the use of such additives, it should be possible to use up to $8 \%$ of ethanol in volume in such mixtures as reported by Cruz (2009) or $15 \%$, according to Abu-Qudais et al. (2007). However, blends involving addition of ethanol to diesel fuel oil also suffer from low cetane number (high ignition delay), which decreases as the percentage of ethanol is increased in the mixture.

One of the possible additives to be used as a binder stabilizer, and also as a cetane number booster, is biodiesel (Cruz, 2009). Among several advantages related to the use of biodiesel it can be cited that: (i) it can reduce the gaseous and particulate emissions (Koike et al., 2010); (ii) it can reduce the dependency of fossil fuels, whose prices tend to increase up to 2035 (United States, 2012); (iii) it is a renewable power source; (iv) it has a good lubricity (AbuQudais et al.,2007); and (v) has a cetane number closer or higher than diesel.

In this study, different blends of diesel, biodiesel and ethanol (both anhydrous and hydrous) were analyzed. The use of ethanol is also justified by the fact that Brazil has a large experience in producing this type of fuel, originated from sugar cane.

\section{EXPERIMENTS}

For this study we used an ASTM/CFR Cetane engine, manufactured by WAUKESHA Co., located in the Thermal Engines Laboratory of the Federal University of Rio de Janeiro (LMT - UFRJ).

This test bench was chosen mainly due to its possibility of varying the compression ratio, fuel consumption rate, time of injection, and air temperature, along several other variables.

\section{Engine}

The engine is a single-cylinder, four-stroke, compression ignition with indirect injection and variable compression ratio. It has multiple fuel reservoir systems. The engine operates on a fixed speed controlled by a synchronous electric motor. Presented below are the main technical and geometrical data for the engine:

- Diameter of cylinder: $83 \mathrm{~mm}$

- Piston stroke: $114 \mathrm{~mm}$

- Volume of pre-combustion chamber: 4.291 $\mathrm{x} 10^{-5} \mathrm{~m}^{3}$

- $\quad$ Piston Speed: $3.42 \mathrm{~m} / \mathrm{s}$

- Engine speed: $900 \mathrm{rpm}$

- $\quad$ Engine weight: $399.16 \mathrm{~kg}(880 \mathrm{lb})$

- Weight of the complete test bench: 1247.38 $\mathrm{kg}(2750 \mathrm{lb})$

- Compression ratio: variable between 8:1 and $36: 1$

\section{Temperature Measurement}

The engine itself has a temperature sensor for the lubricating oil and thermometers to enable the temperature control at some points, such as:

- Intake air temperature: can be controlled by a thermostat on the dashboard of the engine, which is connected to an electrical resistance installed in the intake manifold;

- Cooling water temperature of the engine block: the engine operates with two channels of cooling water, an open circuit to cool the injection nozzle and one closed circuit to the engine block.

\section{Ignition delay and injection timing measurements}

The engine is equipped with a pressure sensor installed inside the combustion chamber, as well as a position sensor installed on the flywheel. By taking the difference between the injection and the start of 
the combustion angles, the engine acquisition system calculates the ignition delay. The same system also measures the start of injection angle by using the information of the position sensor and a needle lift sensor installed at the fuel nozzle. The start of injection can be controlled by a mechanical system while the engine is running.

\section{Fuel flow rate}

The engine has three fuel tanks, which makes the test of three different fuels possible. During the tests performed in this work the fuel flow rate was adjusted to $13 \pm 0.2 \mathrm{ml} / \mathrm{min}$ for all blends, when determining the cetane number, as recommended by ASTM/CFR D613 standard (ASTM Standard, 1985). However, for emissions analysis, the fuel flow rate was adjusted to be the same value found for a blend with $5 \%$ of biodiesel and $0 \%$ of ethanol. In other words, for emission analysis, for all blends used in this work, the fuel pump mechanism was kept with all its settings adjusted the same way as for B5, in order to simulate a real-world engine usage situation.

\section{Gaseous emissions measurement}

In this work, a TESTO 350XL portable gas analyzer was employed. This device uses a nondispersive infrared analyzer (NDIR) and electrochemical sensors, to measure $\mathrm{NOx}, \mathrm{CO}_{2}$, and $\mathrm{CO}$.

\section{RESULTS AND DISCUSSION}

The biodiesel used in this work was obtained by a transesterification process of soybean oil, conducted at the IVIG Laboratory from COPPE/UFRJ. Tab. 1 shows some of the properties of such biodiesel, when analyzed by the GREENTEC Laboratory from UFRJ's School of Chemistry, where it can be noticed that the water content and the acidity, that is a function of the water content, are above the legislation limits. Although these results could have a negative impact in an engine exposed to this particular biodiesel over a long period of time, their interference is not significant when using it for short-term tests. Tab. 2 shows the density of the three fuels used in this work.

Table 1. Properties of biodiesel.

\begin{tabular}{|l|c|c|c|}
\hline \multicolumn{1}{|c|}{ Property } & Method & $\begin{array}{c}\text { Requirements } \\
\text { according to } \\
\text { Brazilian } \\
\text { legislation }\end{array}$ & Results \\
\hline $\begin{array}{l}\mathrm{v} \text { at } 40^{\circ} \mathrm{C}, \\
\mathrm{mm} / \mathrm{s}\end{array}$ & $\begin{array}{c}\text { ASTM-D } 445 \\
\text { EN } 3104\end{array}$ & $3.0-6.0$ & 4.23 \\
\hline $\begin{array}{l}\text { Water content, } \\
\mathrm{mg} / \mathrm{kg}\end{array}$ & $\begin{array}{c}\text { ASTM-D } 6304 \\
\text { EN } 12937\end{array}$ & 200 max. & 1070 \\
\hline $\begin{array}{l}\text { Acidity index } \\
\mathrm{mg} \mathrm{KOH} / \mathrm{g}\end{array}$ & $\begin{array}{c}\text { ASTM-D } 664 \\
\text { NBR } 14448\end{array}$ & 0.5 max. & 1.28 \\
\hline
\end{tabular}

\begin{tabular}{|l|c|c|c|}
\hline Flashpoint, ${ }^{\circ} \mathrm{C}$ & $\begin{array}{c}\text { ASTM-D 93 } \\
\text { NBR 14598 }\end{array}$ & $100 \mathrm{~min}$. & 180 \\
\hline $\begin{array}{l}\text { Carbon } \\
\text { residual, } \\
\% \mathrm{~m} / \mathrm{m}\end{array}$ & $\begin{array}{l}\text { ASTM-D 4530 } \\
\text { NBR 15586 }\end{array}$ & $0.050 \mathrm{max}$. & 0.0065 \\
\hline $\begin{array}{l}\text { Oxidation } \\
\text { stability at } 110 \\
{ }^{\circ} \mathrm{C}, \mathrm{h}\end{array}$ & EN 14112 & $6 \mathrm{~min}$. & 21.87 \\
\hline
\end{tabular}

Table 2. Fuel density.

\begin{tabular}{|c|c|}
\hline Fuel & $\rho, \mathrm{kg} / \mathrm{m}^{3}$ \\
\hline Commercial diesel B5 (S-10) & $822.0 \pm 1.6$ \\
\hline Biodiesel from soybean oil & $874.8 \pm 1.8$ \\
\hline Anhydrous ethanol 99.9\% & $791.5 \pm 1.6$ \\
\hline
\end{tabular}

\section{Cetane number and ignition delay}

Initially the cetane number of several blends of diesel, biodiesel and ethanol was determined using the standard ASTM D613 procedure, which establishes an injection advance of 13 degrees, 13 degrees of ignition delay and a constant fuel flow rate of $13 \mathrm{ml} / \mathrm{min}$. Such results are presented in Tab. 3 and Tab.4. According to the Brazilian standards, the minimum cetane numbers for diesel fuel oil are 42 and 48, for rural and metropolitan applications, respectively. Thus, Tab. 3 and Tab. 4 present in green the blends that conform to metropolitan applications, in yellow the ones that conform to rural applications and finally in red the blends that do not conform to any specification of the Brazilian standards. As expected, the cetane number of the blends decreases as the volume of ethanol increases, as one can verify for each column of Tab. 3 and Tab.4. However, since biodiesel has a higher cetane number than diesel, increasing biodiesel in volume also increases the cetane number of the blends, as one can verify for each line of Tab. 3 and Tab.4. Thus, it is possible to balance, up to a certain extent, the low combustion quality of the blends containing ethanol, by adding more biodiesel to them.

Table 3. Cetane number $(\mathrm{CN})$ of the blends containing $0 \%$ and $5 \%$ of ethanol in volume.

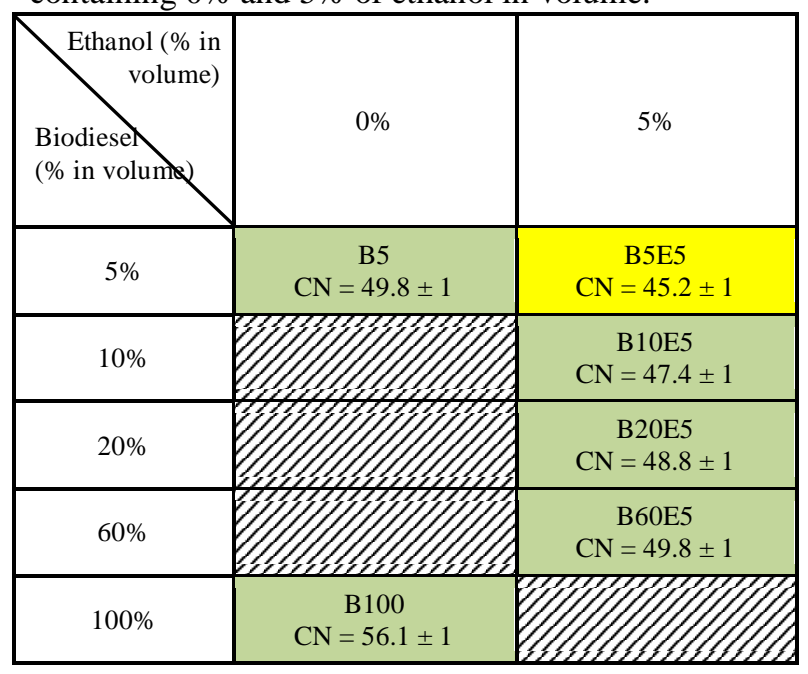


Table 4. Cetane number $(\mathrm{CN})$ of the blends containing $8 \%$ and $15 \%$ of ethanol in volume.

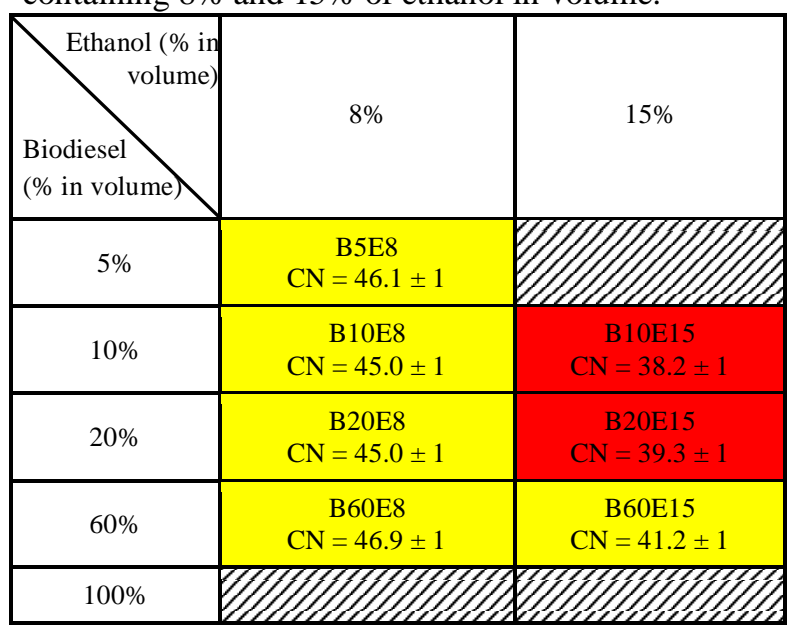

For the ignition delay and gaseous emissions presented next, the engine parameters were fixed to the condition necessary to comply with the ASTM D613 standard for the blend B5. In other words, the compression ratio, injection advance, and other parameters were adjusted in such way that the blend B5 was injected $13^{\circ}$ before top dead center and the combustion initiated exactly at the top dead center. Once this engine condition was obtained for B5, it was kept fixed for all other blends, except for the fuel flow, which was re-adjusted for each fuel so that each one would have a $13 \mathrm{ml} / \mathrm{min}$ flow. This was done in order to simulate a usage of such blends in real engine.

Figure 1 shows the ignition delay of blends analyzed in this work. As expected, the ignition delay increases as the percentage of ethanol is increased, leading to a worse combustion process in compression ignition engines. It is also worth noticing that B100 has the lowest ignition delay. This can be checked looking back at Tab. 4, where it was shown that B100 has the highest cetane number among all blends analyzed. From the analysis of Figure 1 it can also be checked that the ignition delay for B5 is 13 degrees, which is exactly the delay defined in the ASTM D613 Standard. As mentioned before, the engine was tuned to match this condition for the B5 fuel and such configuration was used for all subsequent fuels, while keeping the flow at 13 $\mathrm{ml} / \mathrm{min}$ for each one. This method, however, implied operating the research engine at non-optimal conditions. The expected behavior would be a decrease in ignition delay as the biodiesel content was increased. Besides, an ignition delay increase as the ethanol content of the blends increase would also be expected. This behavior is clearly seen when comparing results for blends with the same volume of biodiesel and varying ethanol contents (B10E5, B10E8 and B10E15, for example). However, when comparing blends with different biodiesel and similar ethanol contents, the results obtained for the B60 blends are unexpected. This could be explained by the harsh conditions the engine was exposed as these fuels, especially for B60E8 and B60E15, were tested. Differently from the other blends, the B60 results fell outside the confidence intervals observed for the other mixtures. It is also worth mentioning that the operation of the engine with B60 caused an excessive vibration in the engine block, indicating a possible stratification of such fuel in the pump system.

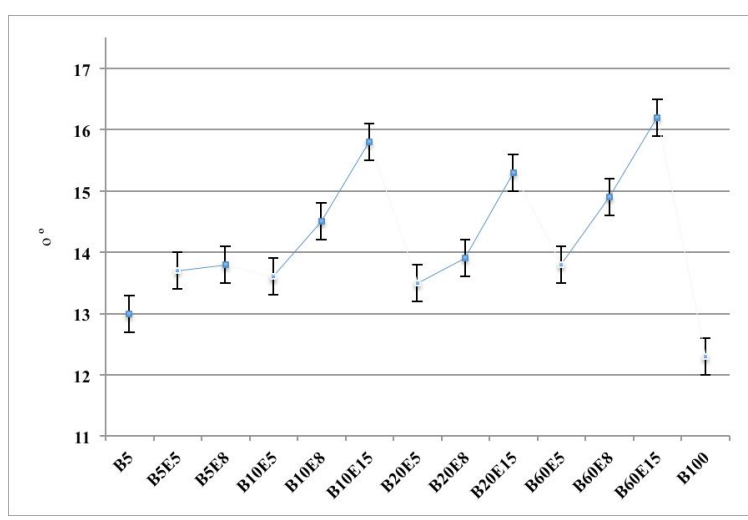

Figure 1. Ignition delay (in degrees).

\section{NOx emissions}

Figure 2 shows the NOx emissions (in ppm) of several blends of diesel, biodiesel, and anhydrous ethanol analysed in this work. This figure presents the results by families of blends, where each family is related to the percentage of biodiesel used. As a general trend, increasing the percentage of biodiesel in the blend leads to higher NOx emissions. This behavior can be associated with the fact that the NOx process is mainly governated by the temperature of combustion and the concentration of oxygen present. Since biofuels are inherently oxygenated molecules, the presence of biodiesel contributes to a higher NOx concentration in the exhaust gases. Regarding the influence of the anhydrous ethanol on the NOx emissions, it was expected that the more ethanol on the blend, the less NOx is emmited. It was observed, however, that, in general, the blend with $8 \%$ of ethanol presented a slightly higher concentration of NOx than the ones with $5 \%$ and $15 \%$.

\section{B5 Family}

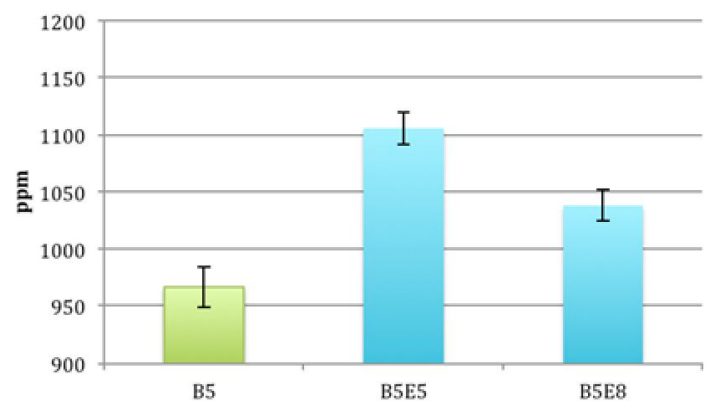


B10 Family

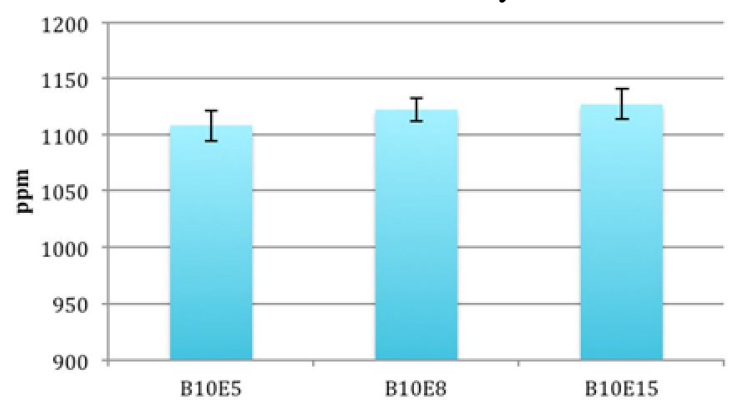

B20 Family

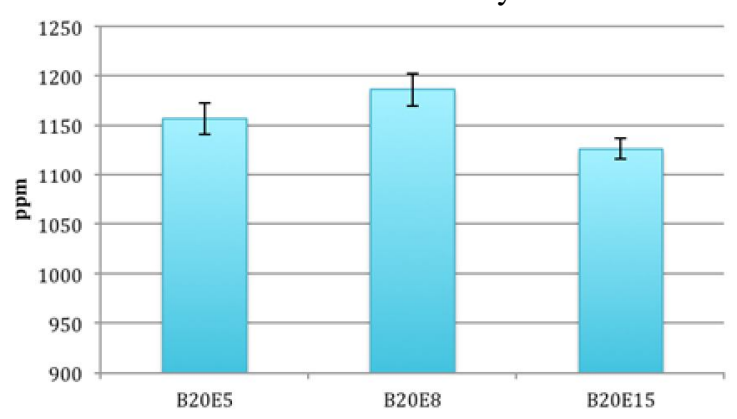

B60 Family

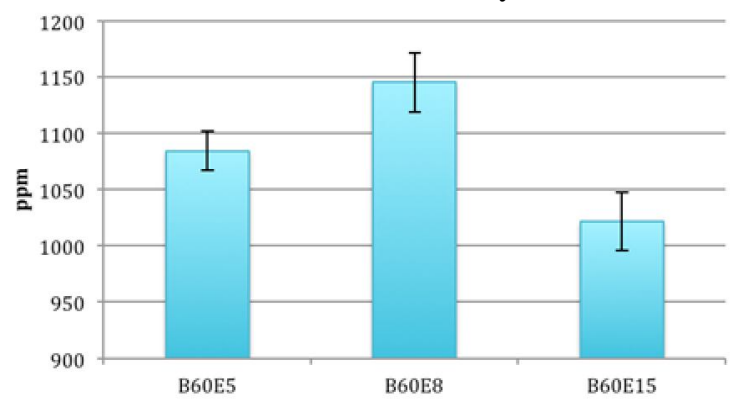

Figure 2. NOx emissions for several blends of diesel, biodiesel and anhydrous ethanol used.

\section{$\mathrm{CO}$ and $\mathrm{CO}_{2}$ emissions}

The influence of the anhydrous ethanol content on the $\mathrm{CO}$ emissions can be observed from the analysis of Fig. 3. As a general trend, as the concentration of ethanol increases, $\mathrm{CO}$ also increases. This could indicate an incomplete combustion, that can be verified from the analysis of Fig. 4, which shows that the concentration of $\mathrm{CO}_{2}$ decreases with an increase in the concentration of ethanol. On the other hand, when the concentration of biodiesel in the blend increases, concentration of $\mathrm{CO}_{2}$ also increases, although there is also a slightly increase in the $\mathrm{CO}$ concentraions. There is clearly a competing process occurring, in which the ethanol deteriorates the combustion quality, since it has a high ignition delay compared both with diesel and biodiesel, while the biodiesel tries to compensate this with its low ignition delay (and high cetane number), compared again both with diesel and ethanol.
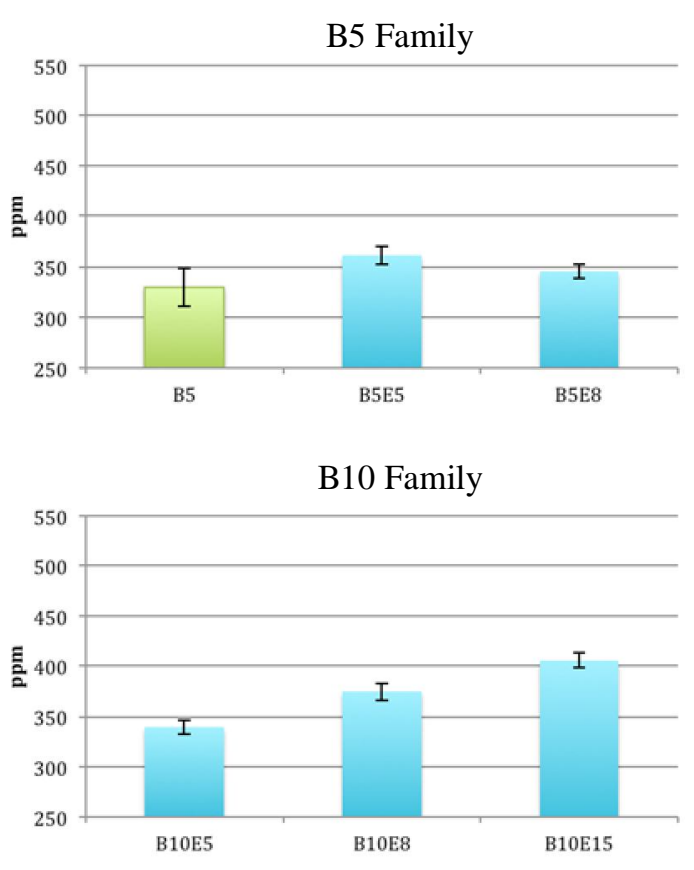

B20 Family

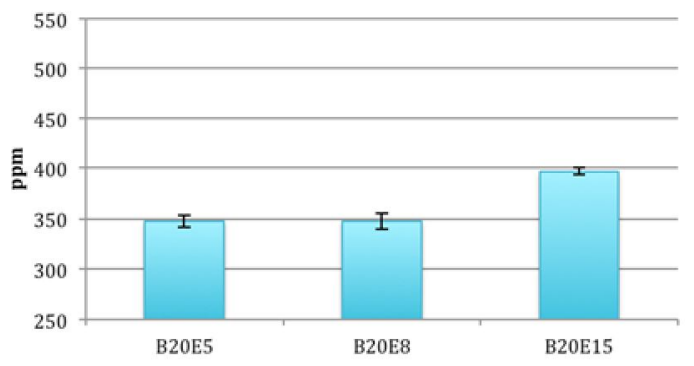

B60 Family

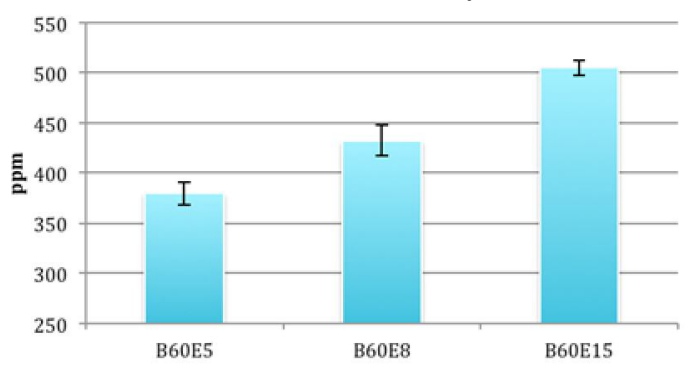

Figure 3. CO emissions for several blends of diesel, biodiesel and anhydrous ethanol used.

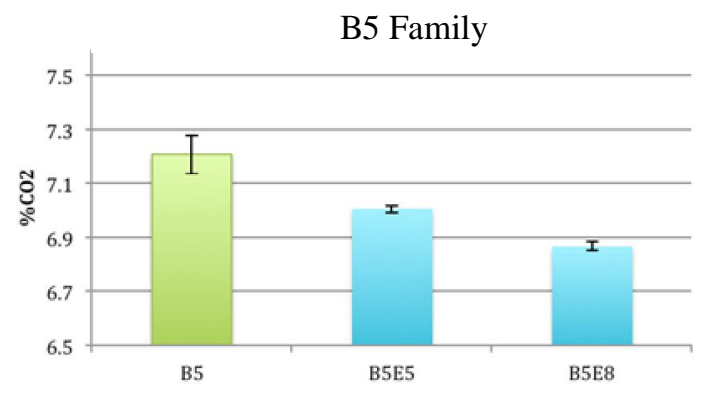



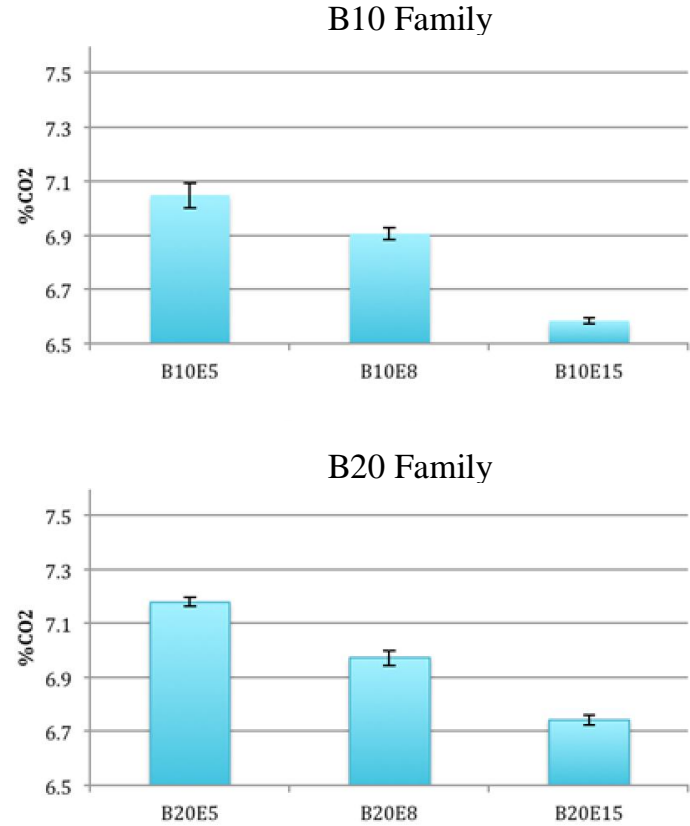

B60 Family

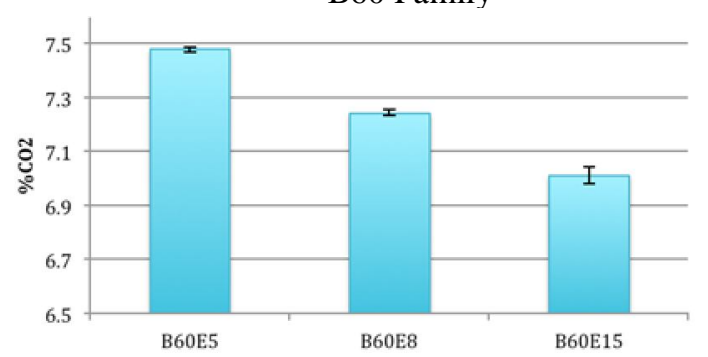

Figure 4. $\mathrm{CO}_{2}$ emissions for several blends of diesel, biodiesel and anhydrous ethanol used.

\section{Anhydrous vs. Hydrous Ethanol}

Results were also obtained for two blends with $60 \%$ of biodiesel in volume. The first blend contained $8 \%$ in volume of anhydrous ethanol, while the second one contained $8 \%$ of hydrous ethanol (which, in turn, had $7 \%$ of water in volume). Tab. 5 shows that, as expected, the cetane number of the hydrous blend decreases, but it still complies with the Brazilian standard for rural applications. In fact, the high content of biodiesel, with its elevated cetane number, contributes to keep the blend within the limits establisthed by the standards. The most important results however are presented in Fig. 5. The presence of water in the blend substantially decreases the emissions of NOx and also decreases the emissions of $\mathrm{CO}_{2}$, keeping the concentration of $\mathrm{CO}$ almost the same, when compared to the anhydrous blend. However, it is worth mentioning that no durability tests were conducted with the blends shown here. The higher amount of water contained in the B60E8H blend could lead to implications regarding the engine life, and thus requires a more thorough long term analysis.

Table 5. Comparison between the cetane numbers of blends containing anhydrous and hydrous ethanol.

\begin{tabular}{|c|c|c|}
\hline Fuel & B60E8 & $\begin{array}{c}\text { B60E8H } \\
\text { (hydrated) }\end{array}$ \\
\hline Cetane Number & $46.9 \pm 1$ & $43.9 \pm 1$ \\
\hline
\end{tabular}

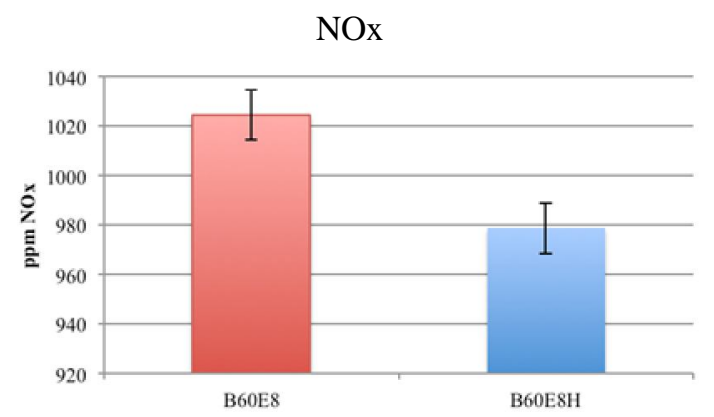

$\mathrm{CO}$

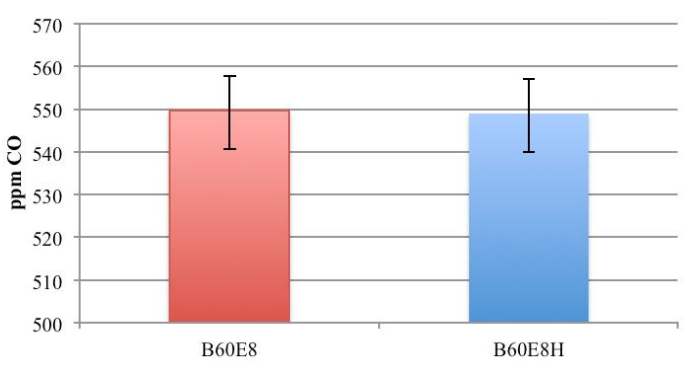

$\mathrm{CO}_{2}$

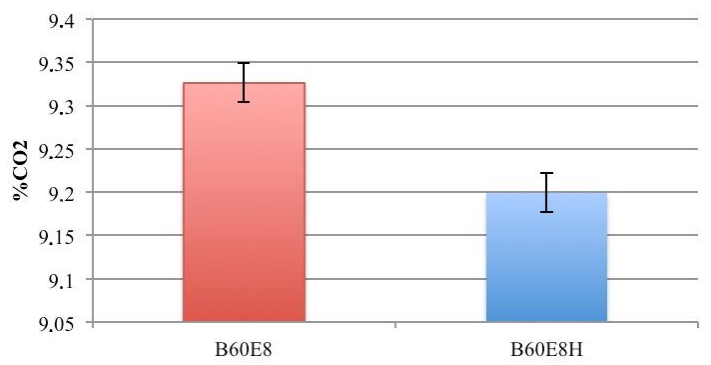

Figure 5. Comparison between the gaseous emissions of blends containing anhydrous and hydrous ethanol.

\section{CONCLUSIONS}

This work presented some results concerning the cetane number, and $\mathrm{NOx}, \mathrm{CO}$ and $\mathrm{CO}_{2}$ emissions of ternary mixtures of diesel, biodiesel and ethanol (anhydrous and hydrous). The use of ethanol could help in decreasing the economic dependence of imported diesel fuels in Brazil. Although the cetane number of ethanol is very low and this fuel has a bad combustion quality when used in diesel engines, the presence of biodiesel, with its high cetane number, partially overcomes those disadvantages, while also providing the necessary stability of the ternary blend in a renewable, environmentally friendly way. The 
use of ethanol, however, causes an increase in the $\mathrm{CO}$ emissions, associated with a decrease in the $\mathrm{CO}_{2}$ emissions, showing that the combustion efficiency probably is worst with its addition. Experiments were also conducted with hydrous ethanol, showing a substantial decrease in NOx emissions, associated with a slight reduction in $\mathrm{CO}_{2}$ emissions. The presence of water in the blend also contributed to a lower cetane number. Nevertheless, such cetane number still complies with the standards for rural applications and those results might indicate that such quaternary mixture has a good potential for further investigations.

\section{ACKNOWLEDGEMENTS}

The authors would like to thank the following Brazilian agencies for the fostering of science: Conselho Nacional de Desenvolvimento Científico e Tecnológico (CNPq), Coordenação de Aperfeiçoamento de Pessoal de Nível Superior (CAPES), Fundação Carlos Chagas Filho de Amparo à Pesquisa do Estado do Rio de Janeiro (FAPERJ), and Programa de Recursos Humanos da Agência Nacional de Petróleo, Gás Natural e Biocombustíveis (ANP/PRH37) for the financial support for this work. The authors also acknowledge the IVIG laboratory for producing the biodiesel used in this work.

\section{REFERENCES}

Abu-Qudais, M., Haddad, O., and Qudaisat, M., 2000, The Effect of Alcohol Fumigation on Diesel Engine Performance and Emissions, Energy Conversion \& Management, Vol. 41, pp. 389-399.

ASTM Standard D613, 1985, Standard Test Method for Ignition Quality of Diesel Fuels By the Cetane Method, ASTM International.

BRASIL, 2014a, Plano Nacional de Logística de Transportes, Brasília, Ministério dos Transportes. (in Portuguese)

BRASIL, 2014b, Dados estatísticos mensais da ANP, Agência Nacional do Petróleo, Gás e Combustíveis Renováveis. (in Portuguese)

BRASIL, 2014c, PROCONVE, Ministério do Meio Ambiente, IBAMA. (in Portuguese)

Cruz, Y. R., 2009, Combustíveis Alternativos: Mistura de Etanol Anidro ao Óleo Diesel para Motores de Ciclo Diesel com Sistema de Injeção de Bomba Rotativa, Doctoral Thesis, Mechanical Engineering, COPPE/UFRJ, Rio de Janeiro, Brasil. (in Portuguese)

Koike, G. H. A., Lopes, A., Passarini, L. C., Camara, F. T., Hildebrand Jr., L., and Bem, A. J. D., 2010, Emissão dos Gases de Combustão em Motor de Ignição por Compressão: Ensaio Comparativo entre Diesel, Biodiesel e Biodiesel com Injeção de Etanol, Revista Minerva, Vol. 7, pp. 11-18. (in Portuguese)

LaPuerta, M., Armas, O., and Garca-Contretras, R., 2007, Stability of Diesel Bioethanol Blends for use in Diesel Engines, Fuel, Vol. 86, pp. 1351-1357.

UNITED STATES, 2012, Annual Energy

Outlook 2012, U. S. Energy Information Administration. 